\title{
Research on Cultivation Mode of Collaborative Innovation between School and Enterprise for Full-time Engineering Master of Material Engineering Specialty
}

\author{
Dong Luan ${ }^{\mathrm{a}}$, Peng Zhang ${ }^{\mathrm{b},{ }^{*}}$
}

Harbin Institute of Technology at Weihai, No.2, West Wenhua Road, High-tech District, Weihai, Shandong, China

a luandong@hitwh.edu.cn, b zhangpeng@hitwh.edu.cn

Keywords: Master of full time engineering, Material engineering, Cooperative cultivation of school and enterprise, Innovation ability.

\begin{abstract}
With the increase of enrollment scale and our country's demand for innovative composite talents, full-time engineering masters are becoming the major source of cadre reserve talents as engineering technology management in enterprises. The requirements for full-time engineering master cultivation are also improving. The cooperative cultivation of school-enterprise and practical innovation training are becoming the hot spot of full-time engineering master cultivation research. This paper analyzes the problems existing in the course system, practice mode, dual tutor system and innovation training of the full-time engineering master cultivation. The school-enterprise collaborative innovation cultivation practice of full-time engineering master was carried out in material engineering major in Harbin Institute of Technology at Weihai by the methods of strengthening course system which focus on engineering application and innovation ability training, building cooperative innovation training bases between college and enterprises, establishing innovative practice process, optimizing dual tutors structure, and perfecting the quality assurance system for full-time engineering master training. It is hoped to provide some reference for other researches on the reform and exploration of full-time engineering master cultivation.
\end{abstract}

\section{材料工程专业全日制工程硕士校企协同创新培养模式研究 栾冬 ${ }^{a}$, 张鹏 $b$, \\ 1哈尔滨工业大学（威海）材料科学与工程学院, 威海, 山东, 中国 aluandong@hitwh.edu.cn, bzhangpeng@hitwh.edu.cn}

关键词：全日制工程硕士; 材料工程; 校企协同培养; 创新能力

中文摘要. 随着招生规模的增加和国家对创新型复合人才需求的提升, 全日制工程硕士正在 逐渐成为我国企业工程技术管理骨干储备人才的主要来源。国家对全日制工程硕士的培养要 求也在逐步提高。校企协同培养和实践创新能力的培养正在逐渐成为全日制工程硕士培养的 热点。本文分析了我国全日制工程硕士培养过程在课程体系、实践模式、双导师体制、创新 能力培养等方面存在的问题, 通过强化侧重工程应用和创新能力培养的课程体系、共建校企 协同创新培养基地、建立创新实践模式、优化双导师结构、完善人才培养质量保障体系等方 式在哈尔滨工业大学（威海）材料工程专业开展全日制工程硕士的校企协同创新培养模式实 践。希望为全日制工程硕士培养模式的改革与探索提供一定参考。 


\section{1. 引言}

自1997年设立工程硕士专业学位以来，我国工程硕士研究生教育经历了试点培养、规模 发展和质量提升三个阶段, 为国家输送了大量高级工程技术和工程管理人才。在经济全球化 背景下，世界各国之间的竞争既是综合国力的竞争，更是创新型人才的竞争。社会对高校毕 业生的要求除了应具备扎实的知识基础外, 还需要具有较强的实践能力和创新能力。为进一 步推进学位与研究生教育改革与发展, 更好的适应我国经济建设和社会发展对高层次应用型 人才的需要, 并逐步建立健全具有中国特色的专业学位研究生制度。2009年, 教育部下发开 始招收全日制工程硕士的文件和一系列的管理文件, 提出用5年时间使全日制专业学位硕士研 究生与学术型硕士研究生的招生比例达到 $1: 1$ 。全日制工程硕士将逐渐成为向企业输送工程技 术和工程管理人才的重要来源。所以, 全日制工程硕士培养质量的提升对于社会的发展具有 重大意义。

\section{2. 我国全日制工程硕士培养现状}

世界研究生教育大致经过了德国的学徒式、美国的专业式以及后来被广泛采用的协作式 三个阶段, 培养理念逐渐由专攻工程应用向科研与工程并重的双重方向发展。我国以协作式 为原型进行了10余年的探索, 目前主要采取依托于产学研合作的校企联合培养模式, 生源以 应届本科毕业生为主。2009年，教育部发布开始招收全日制工程硕士的有关文件并逐步将全 日制工程硕士作为企业输送工程技术和工程管理人才的主要来源。但是, 由于我国全日制工 程硕士的培养发展时间依然较短, 培养模式尚未成熟, 校企联合培养工程硕士仍普遍存在一 定问题，导致不少毕业生就业后无法较快适应以工程应用和产品技术研发为主导的工作模式， 造成其在企业的成长困难, 有的甚至被逐渐埋没, 这对社会造成了一定的人才损失, 同时也 有悖于国家对于全日制工程硕士研究生的培养初衰不利于该类研究生培养的良性发展。

\section{1 培养体系过度借鉴学术型硕士, 缺乏工程应用的针对性}

目前国内高校对于全日制工程硕士的培养与指导模式的制定依据主要来源于以往工程硕 士的培养经验, 全日制工程硕士的培养方案和课程体系的建立主要通过对现行的学术型硕士 课程体系进行修改得到的, 两套授课体系所使用的教材和授课内容大致相同, 课程体系缺少 侧重于实际工程应用的针对性, 缺少依托于专业领域背景的创新类启蒙课程, 研究生不能够 很好地将所学理论与实践相结合, 在本领域内科研和技术创新方面缺少思维启蒙和创新精神 的培养。

\section{2 实践质量保障体系不完善, 缺少创新能力培养}

目前国内全日制工程硕士与学术硕士主要差别在于专业实践, 工程硕士的核心培养环节 也是实践。由于高校和企业在工程实践方面的目标和需求存在一定差异, 高校希望企业能为 人才培养提供资金、实习场所等资源。企业则主要以盈利为目的, 希望能够通过校企合作实 践获得一定技术支持和劳动力资源, 然而这种需求相对较难满足, 从而导致企业的切身利益 难以保障, 导致企业在校企合作参与过程中的驱动力不足, 研究生不能通过工程实践提升自 身的综合能力。研究生在企业常被当作普通员工对待而只从事单一工作, 按照要求完成工程 任务, 不能深入接触企业实际工作环境, 缺少自主探究和运用知识理论解决实际工程问题的 环节, 不利于研究生毕业后的进一步成长, 阻碍了延续性校企协同培养成果的培育。

\section{3 校外导师指导模式简单, 缺少有效交流}

目前国内全日制工程硕士的培养要求采用双导师制, 由学校从企业聘任校外导师负责实 践指导, 研究生在校指导由校内导师负责。但是, 实际上导师只是简单在自身职责范围内进 行指导。校企导师缺少有效沟通导致很多校外导师只是流于形式, 很难体现校企协同指导培 
养的优势。目前国内高校在全日制工程硕士培养的相关制度方面还处于优化完善阶段。由于 工程硕士偏于应用, 各高校、专业、合作企业也有自身特殊性, 所以很难制定一套通用的管 理制度，需要高校专业自身探索一套适合自身特性的制度体系。

\section{3. 校企协同创新培养模式实践}

\section{1 全日制工程硕士的培养目标}

全日制工程硕士的培养目标是具备一定的研发能力, 能够从事材料领域的科研开发、技 术改良创新、工程规划管理的高层次工程技术和工程管理人才。全日制工程硕士的培养体系 也应该围绕重视工程应用、提升工程管理与创新能力为核心来构建, 将创新能力的引导培养 渗透到各培养环节。

\section{2 强化侧重工程应用和创新能力培养的课程体系建设}

依据全日制工程硕士的培养目标, 在培养过程中要提升研究生创新实践能力和先进的企 业管理理论水平，建立适用于工程技术管理型创新人才培养目标的课程体系。哈尔滨工业大 学 (威海) 在材料工程专业全日制工程硕士课程体系建设中, 以高层次技术和管理人才需具 备的综合素质为目标, 以应用和市场就业为导向对课程结构进行优化, 建立应用基础课程、 应用专业课程、先进管理理论、现代应用技术专题讲座课程体系。在夯实本专业重要基础理 论的基础上, 强化研究生在实际工程环境、现代工程技术应用、现代企业管理理念、先进技 术发展与应用现状等方面的认识。部分专业课程引入创新性实验环节, 在保证研究生掌握相 关基础理论的前提下, 自主开展实际工程问题的探究与解决方法提出, 实验报告作为课程考 核环节之一。邀请在材料工程领域和研究生创新能力培养领域具有深厚理论功底与教学经验 的教授主讲创新思维与创新精神的创新实践类课程。引导研究生将所学知识应用于解决实际 工程问题并在解决问题的过程中启发创新性思维，提升自身的创新实践能力。

\section{3 校企协同创新培养基地的共建}

校企协同培养基地的共建有利于实现硬件资源的优势互补，为工程硕士提供更加完善的 综合性应用创新平台, 发挥高校侧重基础研究与学术创新和企业侧重规模化生产及工艺创新 的特色, 为工程硕士提供具备优秀设计能力、先进分析测试能力、高效方案推广实施能力的 综合性创新实践平台。为各类工程创新方案的实施与验证提供更好的平台基础, 为工程硕士 提供更好的自主探究创新环境。哈尔滨工业大学 (威海) 材料科学与工程学院现有先进焊接 与连接国家重点实验室、海洋工程材料及深加工技术国际联合研究中心、山东省特种焊接技 术重点实验室、“军民两用新材料及制品”山东省高等学校重点实验室、威海市工程技术研 究中心3项, 并与萝北云山碳业有限公司、山东核电有限公司、威海万丰镁业科技发展有限公 司、山东大王金泰集团、中通客车控股股份有限公司、威海联桥集团、威海银兴集团等多家 企业建立了稳定的合作关系, 开展了研究生联合培养基地共建, 保障了研究生工程实践的需 求, 促进研究生教育与社会需求相结合, 培养了研究生工程实践能力和创新能力。

\section{4 全日制工程硕士的创新实践模式建设}

针对校企协同培养过程中企业驱动力不足的情况, 开展以横向项目研究为基础, 传统认 识实习与工程实践和学位论文相结合的实践教学模式。哈尔滨工业大学（威海）材料工程专 业近 5 年年均主持或参与横向项目 30 余项, 年均横向科研经费 1000 余万元, 较为全日制工程硕 士的工程实践和学位论文选题提供了大量的素材和经费支持。以企业技术需求的横向课题研 究为基础, 选取难度适当的素材作为全日制工程硕士工程实践和学位论文题目, 在调动企业 参与的积极性的同时, 导师可以在完成项目的同时对研究生的学位论文和工程实践进行指导, 
研究生能够切实参与实际工程项目的研究过程, 提升自身解决实际工程问题的能力和创新能 力。

\section{5 双导师结构的优化}

针对全日制工程硕士在理论和实践方面的不同培养要求，采用双导师制进行培养。选择 具有丰富校企合作经验的校内研究生导师为校内导师, 主要负责研究生的课程选择、论文发 表、学位论文的修改、论文创新性评价及答辩。为适应国家培养应用型研究生人才的需求, 在北京赛福斯特技术有限公司、北京钢研高纳科技股份有限公司、烟台一诺电子材料有限公 司、山东航天电子技术研究所等单位聘请具有扎实理论基础和丰富工程经验的高级工程技术 管理人员作为校外兼职导师, 主要负责研究生在工程实践期间的指导, 突出工程实践环节, 切实参与解决生产实际问题。研究生的学位论文选题由两位导师共同商定, 校外导师参与研 究生学位论文的审阅与答辩, 主要审核论文中关于工程实践问题的完成情况及研究成果的工 程应用价值。学院定期邀请校外导师与研究生和校内导师进行技术交流, 介绍先进工程技术 及装备在企业的实际应用情况和现存的技术难题, 让在校师生更多的了解企业的实际工程生 产情况, 开阔在实际工程应用及装备领域的视野, 加强企业与高校间的技术交流, 发现新的 工程实践题材和潜在的成果转化方向。

\section{6 全日制工程硕士的人才培养质量保障}

全日制工程硕士的各培养期间是在各部门的合作下完成的, 从论文的开题到答辩与评审 等主要环节都要有学校、企业或科研院所等教学管理部门的参与, 任何环节或部门出现失误 可能会对最终培养结果产生较大影响。所以, 全日制工程硕士人才培养质量保障体系的建设 尤为重要。

校内导师招生资格审核除满足基本条件外，还应当着重考查导师的横向项目研究基础、 与企业合作紧密程度、技术成果及转化情况等问题; 校外导师招生资格审核主要考查导师的 工程背景、工程技术经验、工程管理经验等问题。工程硕士的学位论文除了需要具备一定的 理论水平和创新点以外, 更应当重视实际技术需求和应用价值, 研究生学位论文要经由校内 外导师协同选题, 同时将工程实践部分规划学位论文体系当中, 校内导师主要审核论文的理 论水平及创新情况, 校外导师主要审核论文的工程实践情况及成果应用价值。研究生的学位 论文答辩要通过两位导师的共同审批, 注重考查学生的综合素质, 即科研理论与工程应用能 力的体现。

\section{4. 结束语}

本文介绍了我校材料工程专业全日制工程硕士校企协同创新培养模式的探索与实践，通 过应用类课程体系的优化、建立以横向项目研究为基础工程实践与学位论文相结合的创新实 践教学模式、双导师分工结构的优化、人才培养质量保障的完善, 全日制工程硕士的培养质 量得到保障。后续实践过程中还需要在生源政策、导师指导能力建设、学位论文评价体系等 方面进行改革和实践, 不断提高材料工程专业研究生培养质量, 满足社会需求。

\section{致谢}

本文为哈尔滨工业大学校级教学研究项目《全日制工程硕士校企协同创新培养基地建设 模式探索》(JGYJ-201652)的阶段性成果之一。 


\section{References}

[1] L. Yang, Y. M. Sun and X. P. Chen, Innovation and exploration of on-site teaching course of full-time engineering master enterprise practice base, Academic Degrees \& Graduate Education, vol.2,pp. 35-39, 2014.

[2] X. L. Wu, Z. F. Ning and T.J. Yong, Creating the excellent engineering master education brand rely on the unique advantages - taking the field of petroleum and natural gas engineering as an example, Academic Degrees \& Graduate Education, vol.8, pp. 32-35, 2012.

[3] J. Li and X.X. Mu, Study on the management mechanism of the practice ability training for full-time engineering postgraduate students, Heilongjiang Researches on Higher Education, vol.12, pp. 112-116, 2013.

[4] A. F. Zhang and C. Liu, New engineering construction under the background of "Made in China 2025", China University Teaching, vol.9, pp. 21-23, 2017.

[5] J. Chen, S.Y. Zuo, G. L.Yang and W. B. Shi, Exploration and practice of school-enterprise collaborative training model for full-time master's degree graduates - taking geological engineering major of Guizhou university as an example, Survey of Education, vol.1, pp. 5-7, 2017.

[6] Y. Deng and M. Wu, Study on the joint training quality assurance system of full-time engineering master, Heilongjiang Researches on Higher Education, vol.10, pp. 134-136, 2014.

[7] Z. Q. Wang, Y. D. Sun and J. Yao, Exploration and construction of modern high level engineering talent training mode - taking the reform practice of University of Shanghai for Science and Technology as an example, Journal of Graduate Education, vol.26, pp. 70-73, 2015.

[8] J. M. Li, C. J. Duan and C. Liu, The exploration of training mode of graduate students in mechanical engineering based on collaborative innovation mechanism, EDUCATION TEACHING FORUM, vol.33, pp. 44-45, 2015.

[9] Y. H. Wen, X. L. Wu, C. Z. Qi and W. L. Shi, Study on the cultivation practice of professional degree graduates with professional requirements - taking the training of full-time engineering master of China University of Petroleum as an example, JOURNAL OF NATIONAL ACADEMY OF EDUCATION ADMINISTRATION, vol.5, pp. 80-85, 2016.

[10]C. N. Jing, J. C. Fan, S. H. Wang, L. S. Zhao and B. Xv, Research on the collaborative cultivation model of material engineering degree, JOURNAL OF SHANDONG JIANZHU UNIVERSITY, vol.29, pp. 98-105, 1977.

[11]M. Li, B. X. Lin, S. Z. Wang and B. W. Chen, Collaborative innovation training of professional postgraduate students, Journal of Higher Education, vol.5, pp. 11-13, 2018.

[12]J. Yang and L. Z. He, The construction of practical teaching system for cultivating innovative talents under the cooperation of universities and enterprises, FORUM ON CONTEMPORARY EDUCATION, vol.283, pp. 107-112, 2018. 